\title{
Numerical simulation of the reconstruction bank-protection type grillage on canals and rivers of St. Petersburg
}

\author{
Vladimir Korovkin \\ St. Petersburg State Polytechnical University, 195251, St. Petersburg, Russian Federation
}

\begin{abstract}
Reconstruction of urban waterfronts in St. Petersburg, built in the beginning of the last century, is relevant. In the technical literature and departmental document each type of mooring hydraulic structure has its own method of calculation. Shown the practical implementation of engineering universal method of calculating berthing quays. The proposed generalized model piles in the soil, which under the action of horizontal load rotates as a rigid body and at the same time bends as a flexible rod. Kind of movement depends on the flexural rigidity of the piles and stiffness of the soil. The position of the elastic line of the pile depends on the nature of the upper sealing. The stiffness of soil from the entire cycle, the load on the piles is determined from the curve the load- displacement
\end{abstract}

Keywords: city quay, coefficient of soil stiffness, generalized model of the piles, low pile grillage, pile foundation.

\section{INTRODUCTION}

Embankments of the city St. Petersburg are many of kilometers designs in the form of pile foundation, built at the beginning of the last century. Restoration of the historic appearance of buildings and structures of the city requires the preservation and renovation of the specified type of finishing off the coast and canals.

Refinement calculation reconstruction bank protection in the form of low-pile raft foundation is the actual problem

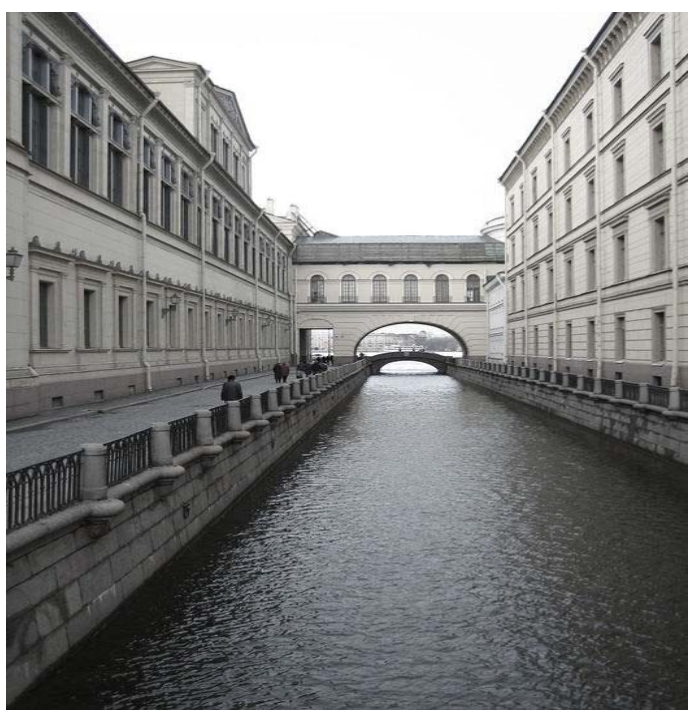

Fig. 1. Winter Canal with a bridge hanging over him and Arch.

\section{DESCRIPTION OF THE OBJECT OF STUDY}

The object of study is the construction in the form of a low piles raft foundation in the ground. Figure 1 presented on the coast canal to St. Petersburg using shore protection structure in the form of low-pile raft foundation.

Arch of two bank protection combines two buildings - the Old Hermitage, built Y. Felten in 1771 1787, respectively, and the Hermitage Theatre, built by Giacomo Quarenghi in 1783-1787 years. City boardwalk, preserving the building is of rubble concrete grillage on wooden piles. Obviously, this is a beautiful architecture, but still associated in the public mind with the "Queen of Spades" and not so much of Pushkin as Tchaikovsky must be maintained forever. In modern cities in a dense housing is becoming increasingly urgent problem of high-rise buildings, requiring load transfer to the deeper layers of soil base. A number of cities, including St. Petersburg, with its numerous channels, have complex conditions for the construction of modern buildings and urban waterfronts, due to the presence of a thick layer (15-20 $\mathrm{m})$ of weak clay soils. It makes use of pile foundation.

Enhancing the relevance of this topic is due to the rapid growth of the number of storeys of buildings, including the installation of pile foundation. In relation to the city waterfront of St. Petersburg practical interest as the reconstruction of existing embankment rivers and canals so and the construction is of concrete grillage on piles. 


\section{THE AIM OF THE WORK}

In the technical literature $[1,2,3]$ and in the departmental normative documents $[4,5]$, each type of ports hydraulic structure has its own method of calculation. When translating the manual is based on a significant portion of the computers calculation is made on the terms and assumptions that were laid in the era of the lack of computers [6- 8].

To simplify the understanding of the mechanism of interaction of structural elements with the ground and maximize the use of computers was proposed in 2002 , the engineering universal method of calculation, which can be applied to any structure mooring quay [9] and with utilization in the work $[10,11]$.

The essence of the calculation is that any mooring quay consists of separate elements - joist of different stiffness from perfectly flexible (anchor rod) up to absolutely rigid ( rigid rigel).

Condition rod interaction with other elements of the mooring quay can be various. They include different types of supports and the subgrade. Specific combination of rods connected to each other as a condition of joint deformation of structural elements so and the structure itself whole, each of which has different forms of interaction between them. This approach unifies computational methods and thus eliminates the need of some simplifications adopted in exist in calculation.

For example, bolverk is a system from fixed by a flexible rod and of two vertical rods.

Wall - a balk of finite stiffness, with the top support and in the lower part, respectively - in the ground. Anchor rod - flexible rod which leans on the sandy soil. Anchor wall - balk finite stiffness, which is located in a homogeneous or inhomogeneous ground.

The purpose of this paper is the practical implementation of engineering universal method of calculation of mooring quays in relation to the urban waterfront as a low pile raft foundation so and the possibility of using the method in the pile foundations of the highrise buildings. Assesses the impact of the assumptions used in the departmental document.

\section{REVIEV OF THE LITERATURE}

N. Gersevanov first gave a general solution to the problem of calculating pile of the embankments grillage type, treating them as a frame on the racks with fixed sealing up (1913). He received three canonical equations of method deformation, taking the unknowns displacement vertical, horizontal and rotate of the structure. The solution of the equations allowed us to obtain all forces in the piles.

Russian scientists B. Lozovskiy, F. Dimentberg, V. Khristophorov et al. proposed graphics solutions. Methods of calculation, developed N. Vyunshem, C. Nekkentvedom are special cases of solutions $\mathrm{N}$. Gersevanov. These decisions involve the transfer of the coordinate in the elastic center, which reduced the number of canonical equations of deformation.

V. Skuratov and N. Shaposhnikov offered calculation flexible pile grillage. Pile design with an elastic fastening regarded as an ordinary multi-span frame with elastic supports, in which each node has an independent vertical displacement and rotation, and also are common to all nodes of the frame horizontal movement.

Approximate methods of calculating these structures proposed by V. Skuratov, F. Dimentbergom, N. Smorodinskii, S. Antonov and others used before the advent of computers. In order to simplify the calculations used different assumptions, which do not give a correct picture of the construction work and creates significant errors in the effort elements.

The author of this article proposed an approximate calculation of a pile structures irrespective of the hardness of the top structure, the development of ideas N. Smorodinskii (1949). The calculation uses the method of separation of design elements and their subsequent gluing and the superposition of loads..

Method N. Gersevanov in relation to low grillage used in regulatory guidance on the design of pile foundations and as adopted by the coefficient of subgrade serves the secondary purpose for finding the estimated depth of seal piles [12].

In recent years, associated with the calculation of pilegrillage, typically use a classic design scheme [13]. Works of foreign scientists, devoted to the calculation of piled embankments [14 - 17].

Significant progress has been made in recent years in methods of calculation, design and construction of pile foundations. New or improved methods of analysis and design of pile foundations designed, based on extensive experience with the use of piles in various soil conditions. Method of calculation of pile foundations under the first and second limiting conditions has important theoretical and practical importance.

Work in the field of soil mechanics scientists B. Berezantseva, M. Goldstein, M. GorbunovPosadowa, B. Dolmatova, N. Tsytovich and many others provided a basis for improvement of the methods of calculation of piles. Systematization of research results and improvement of methods of calculation of piles foundations performed V.A. Barbashov, A. A. Bartholomay, G. I. Glushkov, V. N. Golubkov, A. A. Meadows, etc.

However, in many cases, the projects pile foundations are with large stock, reducing the economic efficiency of the use of piles, indicating the need for further improvement of methods of their calculation.

\section{THE MECHANISM OF PILE FOUNDATION WITH GROUND}

The author proposed a generic model of the behavior of piles in the ground. Pile under horizontal load action rotates as a rigid balk and simultaneously bends 
as a flexible rod. The offset of the top of the pile is the sum of:

$$
\Delta=\Delta_{1}+\Delta_{2}
$$

where $\Delta_{1}$ is the displacement of the piles from turning; $\Delta_{2}-$ displacement piles from bending.

The amount of movement depends on the ratio of flexural stiffness of the piles and deformation characteristics of the soil (stiffness) (Fig. 2, a). Experiments A. H. Zarkhi (1954), shows which increase the flexibility of the wall causes an increase in jet pressure of the soil in the upper layers, more passive pressure (Fig. 2, b).

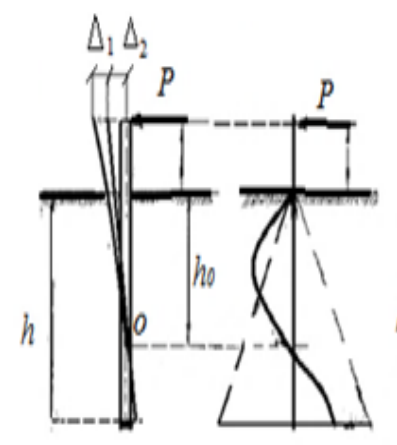

a)

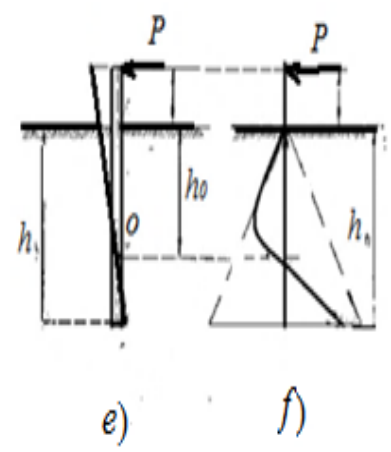

e)

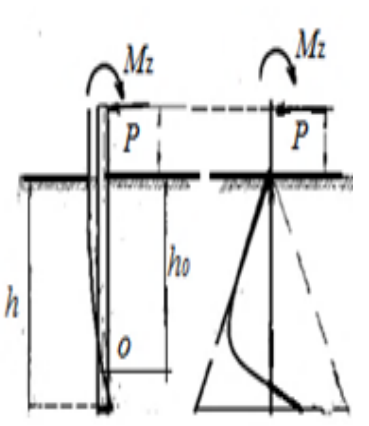

d)

c)

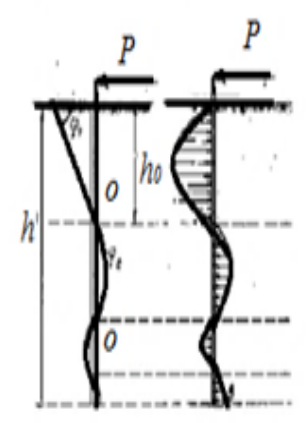

g)

h)
Fig. 2. Generalized model of behavior of the piles in the ground. a, b) The position of the elastic line and curve of earth pressure on the pile of finite stiffness from the force $\mathrm{P}$; $\mathrm{c}, \mathrm{d}$ ) Also from the force $\mathrm{P}$ and moment $\mathrm{Mz}$; e, f) Too from force $\mathrm{P}$ in a rigid piles; $\mathrm{g}, \mathrm{h}$ ) Too from the force $\mathrm{P}$ in a flexible piles.

The rigel creates in the piles bending moment in the sealing. The position of the piles in the depends on the stiffness of the beams, piles and soil. (Fig. 1c). For example, short rigid piles, embedded in the ground can be displaced parallel to the axis under the action of horizontal load. In another case, they are rotated relative to the zero point changing the sign of the plot of pressure on the pile. (Fig. 2 (d).

If you change the bending stiffness of the piles in the limit $\infty>$ EI $>0$ and consequently - the stiffness of soil from $0<\mathrm{K}_{\mathrm{xy}}<\infty$ behavior of piles in the soil varies from rigid (Fig. 2, e, f) to flexible piles (Fig. 2, $\mathrm{g}, \mathrm{h})$.

In the interests of practical range rigidity of the rigel, piles and the soil there are a large number of options that have different meanings efforts in piles. In the interests of practical range rigidity of the rigel, piles and the soil there are a large number of options that have different meanings efforts in piles.

Classic calculation of piles constructions of the $\mathrm{N}$. Gersevanov, using rigid fixation of the piles in the ground without regard to its stiffness, can be viewed as a individual case, when $\mathrm{Kx}, \mathrm{y}=\infty$ in the sealing,

Experimental studies show that from the action of the horizontal force is short piles rotates as a rigid body with respect to the zero point $h_{0}$ of rotation. Distance $h_{0}$ from this point to the surface is about 0,7 h (Fig. 2, e). Flexible piles gets wavy bending, and the first zero point for approaching them to the surface (Fig. 2, g). Hard short piles considered in relation to the depth of driving $h$ to the diameter $d$ of up to 10 12. Flexible long piles considered respectively with a ratio of more than 10 [18].

Analysis and generalization of results of experimental studies allowed to develop and propose to use in practice engineering calculation method of pile foundation, reflecting the basic laws of their interaction with the soil foundation established of the empirically [19].

\section{SOLUTION OF THE PROBLEM}

Pile grillage can be viewed as a system of a finite number different rods, which linked as joint deformations of structural elements so and deformations the structure as a whole.

Rigel - the rigid balk, which leans on the pile foundation. This balk loaded as external loads, so and internal forces from impact of the pile foundation.

Pile foundation is a system of balks of different rigidity, rigidly fixed embedded in the rigel, and immersed in the soil foundation. Settlement scheme uses of the frame construction with different stiffness crossbar and uprights. The nature of the work structures in the soil is determined by the stiffness characteristics of the rigel, uprights and ground. Additionally taken into account the beneficial effect of between the pile space, which is ignored in the standard method of calculation..

Deformation characteristics of soil. In port hydraulic engineering calculations of constructions interacting with the ground, early was performed only with regard to the first limiting condition. Experiments have shown that not accounting for the deformation characteristics of the soil when you interact with it design distorts the calculation scheme structures.

The software system using continuum model more accurately reflects the actual behavior of the soil under load. However, they are not sufficiently adapted to the calculation of berthing waterworks, due to not taking into account many factors in their work. In the prac- 
tice the calculation of berthing waterworks are use over a simple model Fuss-Winkler using coefficient of subgrade resistance.

Theory analysis of structures lying on the ground with a deformed one and two coefficients of subgrade resistance was developed in the works of A. Dinnik, P. Pasternak, A. Krylov, N. Snitko, V. Vlasov and many others. Among foreign scientists engaged in this task H. Westergaard, H.Bufler, H.Lieb, G.Meier [20], Y. Cheung, O. Zienkiewicz [21], C. Desai, J. Christian [22] and others.

Using in calculations a variable coefficient of subgrade resistance (soil stiffness coefficient) better reflects the operation of the foundation. It is sufficient to choose the law of variation coefficient of subgrade resistance, which provides the desired character of rainfall. However, there are some difficulties, because for this purpose it is necessary to solve the problem in the theory of elasticity. Then select the desired ratio, that makes no sense. The coefficient of stiffness are devoted studies of B. Kositsin (1963), V. Lishak (1964), S. Rivkin (1969), V. Fedorovsk (2000) and others.

Using the program «CROSS» successive approximation procedure applied to foundations can more accurately determine the stiffness coefficient of soil [23]. «CROSS» program is part of the package SCAD Office and provides independent work, and the exchange of data with the integrated strength analysis of structures Structure CAD (SCAD) [24]. The above procedure of successive approximations, in our opinion, is acceptable at low loads to the foundation. Since there is no law changes the stiffness of soil from the full load cycle and is not considered a redistribution of the contact pressure from the edge of the plasticity region.

Author represented the mechanical model of the combined stiffness of the soil (subgrade resistance) for pile foundation. The model has the elastic body Hooke (H) and of the plastic body of the Saint-Venant (SV), besides include structural element (S), which taking of the different degrees of hardening or softening the soil. The model on Fig. 3, what similarly the model adopted for the foundation [25].

Quantity springs in the model are located on a lateral surface of the pile. The number of turns of the springs depends on the depth of the active zone of the soil (Fig. 3,a). The spring resists compression more or less of elastic, when a small external loads. The load increases to the limiting value and changes of the value resistance to compression of springs due from the structural element (S). This leads to a nonlinear plot reactive pressure of the soil. The nature of changes in the relative deformation characteristics of the resistance of the soil on the pile from the load shown in Fig. 3, b.

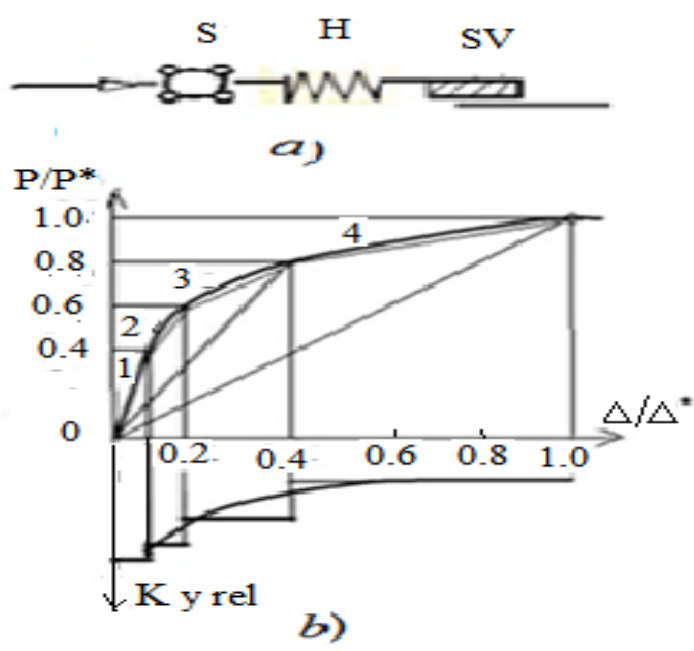

Fig. 3. a) Mechanical model of the combined stiffness of soil, taking into account the structural element. b) Schedule changes in the relative stiffness from the dimensionless curve deformation.

Piles divide the height by the number of plots. Each plot corresponds of the interval on the relative curve deformation depending on the load (Fig. $3 \mathrm{~b}$, top). In the Interval of the curve determines the relative stiffness of the soil $K_{u \text { rel }}$ (Fig. 3 b, bottom).

Values of force $\mathrm{P}$ and deformation piles $\Delta$ allow you to find the coefficient of stiffness of the soil depending on the load.

Example. To calculate the reconstructed waterfront on the canal Griboyedov in St. Petersburg.

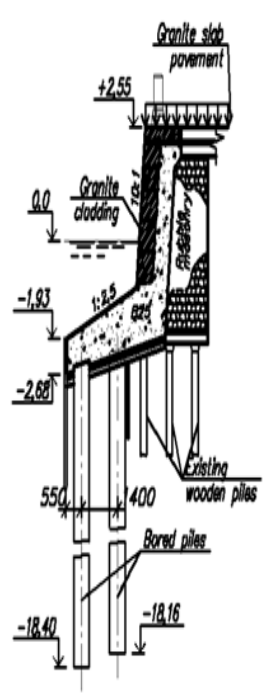

a)

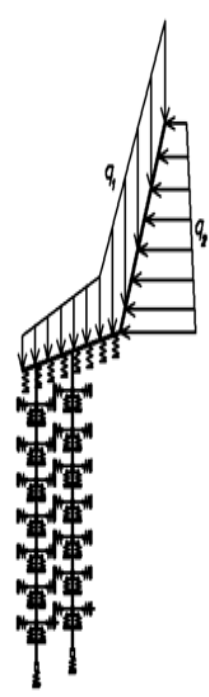

b)

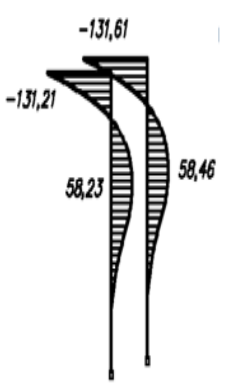

c)
Fig. 4. a) Cross-section of piles grillage. b) Design scheme. c) Bending moment of the diagram in piles.

Initial data. The old quay in the form of hard rubble concrete masonry grillage rests on three rows of wooden piles. The new hard grillage with variable cross-section of reinforced concrete on the pile foun- 
dation of two rows of $0.6 \mathrm{~m}$ diameter bored piles. Step across the line cordon of piles $2.35 \mathrm{~m}$, respectively, and along the cordon $1.4 \mathrm{~m}$.

The strength characteristics of soils are shown in Fig. 3 and the deformation characteristics respectively, taken from [11]. In calculating the existing wooden piles in a margin of safety facilities not taked into account. Results of the comparison of calculations are given in table 1 .

Table 1.

Results of calculations ${ }^{1}$

\begin{tabular}{|l|l|l|l|}
\hline Name & $\begin{array}{l}\text { Calculati } \\
\text { for a SNP } \\
{[11] .}\end{array}$ & $\begin{array}{l}\text { Calcula- } \\
\text { tion for a } \\
\text { generic } \\
\text { method }\end{array}$ & $\begin{array}{l}\text { Program } \\
\text { " Plaxis" }\end{array}$ \\
\hline $\begin{array}{l}\text { Bending moment in } \\
\text { the topic sealing of the } \\
\text { first piles, [kNm] }\end{array}$ & -135.23 & -131.21 & -129.43 \\
\hline $\begin{array}{l}\text { Bending moment at } \\
\text { the topic sealing of the } \\
\text { second pile, [kNm] }\end{array}$ & -135.23 & -131.61 & -129.50 \\
\hline $\begin{array}{l}\text { Bending moment in } \\
\text { the span of the first } \\
\text { pile, [kNm] }\end{array}$ & - & 58.23 & 51.54 \\
\hline $\begin{array}{l}\text { Bending moment in } \\
\text { the span of the second } \\
\text { pile, [kNm] }\end{array}$ & - & 58.46 & 51.9 \\
\hline $\begin{array}{l}\text { The effort in the first } \\
\text { pile, [kN] }\end{array}$ & -470.0 & -417.92 & -410.34 \\
\hline $\begin{array}{l}\text { The effort in the } \\
\text { second pile, [kN] } \\
\text { ment of the top, [mm] }\end{array}$ & 64.16 & 12.02 & 9.08 \\
\hline
\end{tabular}

1.The calculation was performed by student A. Melentev.

\section{ANALYSIS OF THE CALCULATION RESULTS}

Stiffness of characteristics soil, interacting with the piles, and increased flexural rigidity of the piles changed the designs scheme, featured SNP [11]. In particular the moment of fix the bottom of the piles is not apparent. Efforts in piles obtained as in the generic method, using SCAD, so and in Plaxis, were less than in the calculation of the SNP. This had resulted from accounting stiffness characteristics of the soil, interacting with piles.

Comparative calculations of the promenade with various values of the stiffness characteristics of the soil, shows that in the case of flexible piles and dense soil settlement efforts more or less comparable with the calculation SNP 2.02.03-85. In other conditions the computational scheme used in the normative document may not be manifest that, as shown by calculations using the deformation characteristics of the soil, leads to distortion of the forces in piles.

\section{CONCLUSIONS}

1. In the current technical literature and regulations, each type of port hydraulic engineering has its own method of calculation. In first N. Gersevanov was given a general solution to the problem of calculation grillage type of the pile embankments. Treating them as a frame construction with absolutely rigid grillage on racks with rigid bottom seal.

2. Shows the mechanical model of coefficient soil stiffness based on structural element.

3. Shows the method of determining the stiffness of the soil from load on the curve deformation..

4. Shows the practical implementation of the proposed above engineering universal calculation method berthing quays in the low of pile grillage, using the program SCAD. In calculating the deformation characteristics used in the form of horizontal and vertical coefficients stiffness of the soil.

5. Comparative calculations of the promenade with various values of the stiffness characteristics of the soil, shows that in the case of flexible piles and dense soil settlement efforts more or less comparable with the calculation SNP 2.02.03-85. In other conditions the computational scheme used in the normative document may not be manifest that, as shown by calculations using the deformation characteristics of the soil, leads to distortion of the forces in piles.

6. When calculating the structures using a model coefficient bed, special attention should be paid to the reliability of the characteristics of the soil on which depend essentially on efforts and deformation in structural elements. Meanwhile, their values recommended in Rules, have a fairly wide range of values and require adjustments.

\section{REFERENCES}

[1] G.N. Smirnov, V.V. Aristarkhov, S.N. Levichev, A.G. Sidorov, E.A. Korchagin. Ports and port facilities. Ed. DIA, Moscow, 2003, 463 p.

[2] P.I. Yakovlev, A.P. Tyurin, Y.A. Fortucel. Port hydraulic structures. Ed. Transport, Moscow, 1990320 p.

[3] P.P. Kulmach, V. Filippenok, N.G. Zaritovskiy. Marine hydraulic structures. Ch. II, Mooring, offshore and shore protection structures. LVVISU, Leningrad, 1991, $391 \mathrm{p}$

[4] Design of the mooring quays, CH-RF 54.1-85 MRF RSFSR, Moscow, 1991, 247 p.

[5] Instruction on designing marine berthing and shore protection structures. RD 31.31.55.93, MMF, Moscow,1996.

[6] PLAXIS. Plaxis v. 8.2. Finite Element Code for soil and rock analyses. Netherlands, 2002.

[7] Program GEO5 for design and analysis of retaining. Armagrandi and gravitational structures. Certificate of conformity No ROSS CZ.SP.N, Moscow, 2012. 
[8] Program Cluster, version 1, Engineering and consulting centre for Foundation. Moscow, 2005.

[9] V. S. Korovkin. Universal method of calculating berthing quays. The first scientific-practical conference Sea and river ports of Russia, Moscow, 2002, 103-105 pp.

[10] T. Dang, V. Korovkin. Engineering kinematic theory of ground contact pressure in the annexto the hydraulic port facilities. Advanced Materials Research, Vols. 945-949, 2014, pp. 541-548.

[11] A. Melentev, V. Korovkin. Calculation of Retaining Walls with Anchoring at Different Levels. Applied Mechanics and Materials, 725-726, 2015,pp. 185-189.

[12] SP 24.13330.2011. Pile foundations. The updated version of SNP 2.02.03-85. Moscow, 2011.

[13] A.Y. Budin. City and harbourquays Ed. Polytechnic, St. Petersburg, 2014, $418 \mathrm{p}$

[14] CUR-publication 166.Damwand constructies. | ISBN 90376 $0638 \mid$ CUR, Gouda, the Netherlands, 4th issue, 2005.

[15] J. Grabe. Sheet Piling Handbook Design.Thyssen Krupp GfT, Bautechnik GmbH HSP HOESCH Spundwandand Profil GmbH, Hamburg, 2008.

[16] Design Manual. Steel Sheet Piling United States. Stee Updated and reprinted by U. S. Department of Transportation. FHWA with permission, 1984.

[17] A Handbook of Quay Walls. CURCentre for Civil Engineering Research, Havenbedrijf Rotterdam NV,
Gemeentewerken Rotterdam. Published by Taylor \& Francis, the Netherlands ISBN: 978-0-415-36439-3, .2005.

[18] N. K. Snitko. Static and dynamic pressure of the soil. Stroiizdat, Leningrad, 207, 1970.

[19] V.S. Korovkin. Calculation exploited berthing facilities with regard to reologicheskih properties of the base and the harsh climatic conditions of the continental shelf. Ed. SPbGPU, Sankt-Peterburg, 2013. $88 \mathrm{p}$.

[20] H. Bufler, H. Lieb, G. Meier. Frictionless contact between an elastic stamp and elastic foundation. Ing. Arch., Bd. 52, No.1/2, 1982 .

[21] Y.K. Cheung, O.C. Zienkiewicz. Plate and tank on elastic foundation. An application of finite element method Intern. J, Solid structural, vol. 1, No. 4, 1965.

[22] C.S. Desai, J.T. Christian Numerical methods in geotechnical engineering. McGraw-Hill. Inc., 1977.

[23] E. H. Krikunov, A. C. Perelmuter, M. A. Perelmuter, , A. I. Sementsov. Fedorov Century, CROSS-program for determining the coefficients of the bed Magazine of foundation, foundations and soil mechanics, 2002.

[24] N. I. Vatin, U.P. Wash. Joint settlement building and shallow foundations in SCAD. Methodical instructions, St. Petersburg, 2007

[25] V. S. Korovkin Engineering kinematic theory, the contact pressure of the soil in the application to the calculation of certain types of foundations Magazine of civil Engineering, 6, 2013, 39-49p. 